University of Nebraska - Lincoln

DigitalCommons@University of Nebraska - Lincoln

Publications from USDA-ARS / UNL Faculty

U.S. Department of Agriculture: Agricultural

Research Service, Lincoln, Nebraska

2009

Tests of Concepts for Streamflow Sampler Design

John A. Replogle

USDA-ARS

Follow this and additional works at: https://digitalcommons.unl.edu/usdaarsfacpub

Part of the Agricultural Science Commons

Replogle, John A., "Tests of Concepts for Streamflow Sampler Design" (2009). Publications from USDAARS / UNL Faculty. 471.

https://digitalcommons.unl.edu/usdaarsfacpub/471

This Article is brought to you for free and open access by the U.S. Department of Agriculture: Agricultural Research Service, Lincoln, Nebraska at DigitalCommons@University of Nebraska - Lincoln. It has been accepted for inclusion in Publications from USDA-ARS / UNL Faculty by an authorized administrator of DigitalCommons@University of Nebraska - Lincoln. 


\title{
Tests of Concepts for Streamflow Sampler Design
}

\author{
John A. Replogle, F.ASCE${ }^{1}$
}

\begin{abstract}
Total-load sampling has been a perpetual problem in sediment monitoring. Usually a combination of bed-load sampling devices, suspended load suction samplers, and some kind of flume, for total flow rate, is used. Total-load, sediment-sampler-design concepts that can perform all three of these functions are proposed. The resulting designs would require installation at sites that can provide a step-overfall height about equal to the maximum channel flow depth. The concepts are simple, but appear to have been overlooked or ignored for the past many decades, and are based on a moving conveyor belt that is long and wide, with many slots, all of the same size, onto which the stream to be sampled discharges. All flow drops through the slots, and with equal sized slots each must catch a similar proportion of the total flow. Hence, only one slot needs to be collected. As a practical extension it is proposed to replace the conveyor belt with a rack having several slots that represent a short section of the total conveyor belt that is large enough so that the flow does not notice the missing belt parts. This rack is then traversed back and forth on a track through the falling nappe. Laboratory tests of this proposed sampling-assembly rack indicated that the number of the required slots is related to the channel depth and the sum of the slot openings. When the rack is composed of sufficient slots so that the slot-width sum is more than half the channel overfall depth, the system undersampled from 0 to $2 \%$ but when there are insufficient slots whose sum represents less than one-third of the overfall depth, the system undersampled by over $8 \%$. The concepts are extended to the condition with a stopped belt where several sampling-slot groups are equally spaced beneath the overfall. A "test of concept" sampler assembly of the stopped-belt idea was built and tested. The sample catch across the stream was within about $4 \%$ of expected, offering a total load sampling system where motorized equipment is difficult to install, or electric power is not available. Design and construction suggestions are presented. The catch rate can be small enough to facilitate convenient flow measurement of the catch, which can be converted to total streamflow without the need for separate channel flow measurements.
\end{abstract}

DOI: 10.1061/(ASCE)1084-0699(2009)14:1(65)

CE Database subject headings: Sediment; Watersheds; Monitoring; Sampling; Streamflow; Flow measurement.

\section{Introduction}

Sampling streamflows that carry heavy sediment loads usually pose two primary problems. One is the accurate representation in the sample of all sediment sizes present in the source flow, and the other is maintaining a uniform and known quantity ratio between the sampling rate and the flow rate for all discharges. Some sampling systems use a flume or weir for flow rate measurements and some kind of separate sampler for determining the sedimentload characteristics, such as the combination of bed-load sampling devices, used on a large watershed at Tombstone, Arizona, in combination with suspended-load suction samplers (Renard et al. 1976; USDA 1979). Coshocton wheel samplers combined with $\mathrm{H}$-flumes represents one of these systems that have been used widely in studies of soil erosion from small drainage areas of about 1 acre or less. They perform reasonably well under field conditions when properly installed and maintained (Parsons 1954, 1955; USDA 1979). These approaches have been found to have significant sampling errors, related both to the proportion

${ }^{1}$ Research Hydraulic Engineering Collaborator, US Arid-Land Agricultural Research Center, ARS-USDA, 21881 No. Cardon La., Maricopa, AZ 85283. E-mail: John.Replogle@ars.usda.gov

Note. Discussion open until June 1, 2009. Separate discussions must be submitted for individual papers. The manuscript for this paper was submitted for review and possible publication on January 13, 2004; approved on April 25, 2008. This paper is part of the Journal of Hydrologic Engineering, Vol. 14, No. 1, January 1, 2009. CASCE, ISSN 1084-0699/ 2009/1-65-74/\$25.00. sampled, and to the accurate representation of the particle sizes in the sample relative to that in the original flow (Parsons 1954, 1955; Replogle and Johnson 1963: Brown et al. 1970; Wang et al. 1971; Dendy 1973; Renard et al. 1976; USDA 1979; ASCE 1969).

In an effort to remove these limitations on drainage area size, sampling ratio, and particle size biases, total-load sediment sampler design concepts are proposed to not only sample total bed load plus suspended load, but to serve as a flow measuring device, even for irregularly defined channel cross sections.

The concepts are simple, but appear to have been overlooked or ignored for the past many decades. It is hoped that these concepts will assist sampler designers to develop equipment for more extensive evaluations under field conditions.

\section{Theoretical Considerations}

In runoff sampling, the desired information often controls the design concepts. For example, obtaining a time integrated, representative sample of a total runoff event is less complicated than the temporal distribution of the flow rate and sediment transport rate. For the total-event sample, a tank large enough to accumulate the aliquot is all that is needed. For time distribution and flow rate record, the sample volume may require storing in a series of containers that closely approximates the time the sample was collected. 


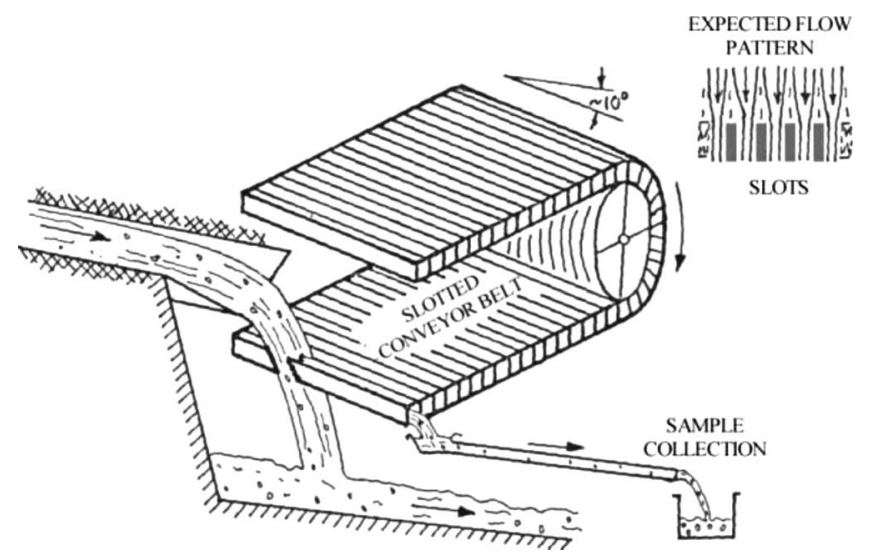

Fig. 1. Hypothetical sediment sampler

\section{Ideal Sampler}

The concepts of an ideal bed-load and suspended load sampler are relatively simple. Imagine that the entire flow can somehow be dumped onto a moving conveyor belt as shown schematically in Fig. 1. In practice, this configuration would probably fail when trash jammed the drive wheels. However, for now, assume the belt is divided into slots of equal width. If the belt travels at a constant velocity, each slot necessarily must collect an equal share of the discharge. Thus, flow from only one slot needs to be collected for record and analysis. Note that channel shape at the overfall can be irregular. Note also that the accuracy of the following described concepts is based on steady flow rate, or slowly changing flow rate, relative to the belt speed.

\section{Belt Speed}

The speed of the belt should have little effect unless it is so fast that it splashes the water and sediment beyond the boundaries of the belt. Water splashed or accelerated from one slot will go down another some distance away.

\section{Effective Slot Width}

The effective slot width is the distance from the center of one slot to the center of the next, including the wall partitions. The partitions need not be thin, or sharp, because any flow striking a partition top must eventually fall down a slot. Because of confining pressures of adjacent flow elements, the flow cannot readily spread in a direction lateral to the flow. Thus, the slot-entry backpressures from the nonsharp partitions are compensated as the flow spreads in the downstream flow direction to use a wider portion of the conveyor belt. The angle of attack in any direction of the falling water jet is of no consequence. Again, the total flow must fall into the slots. Thus, the tilting away from the flow at about $10^{\circ}$, as shown in Fig. 1, is a practical way to handle trash and rock sizes larger than the chosen limits to be sampled.

\section{Slot Opening}

Slot opening, as opposed to the effective-slot width, affects the maximum size of sediment particles collected. Larger rocks, sticks, and stalks are expected to slide down and off the downslope side of the belt.

\section{Discharge Record}

Imagine that each slot discharges into a separate tank. At the end of the flow event, the entire runoff would be stored in these tanks and their contents would all be essentially equal in volume and sediment content, provided the slot collection times were short relative to any changes in discharge rate. Thus, any one tank would contain a share of the runoff event equal to the effective slot-width share on the belt. For example, a $10 \mathrm{~m}$ long belt with 1,000 slot openings centered at $1 \mathrm{~cm}$, including partitions, would collect 0.001 or $0.1 \%$ of the total discharge. Secondary equipment can provide time-related flow records.

\section{Sample Size Adjustment}

The sample size may be inappropriate. Usually it is too large. The sample size can be reduced in several ways. The effective slot widths can be decreased, thus, increasing the number of slots for a given belt length, either by narrowing the partitions or the slot openings, making them smaller relative to the belt length, but this limits the size of particle sampled. Alternatively, the belt length can be increased, while holding the belt speed constant, which again reduces the ratio of effective slot width to total belt length and proportionately reduces the total sample size, even though it would not necessarily reduce the catch volume on a single cycle. Lengthening the belt will increase the return time of a sampling slot and may reduce the precision of flow rate determinations. Note that increasing the belt speed does not change the proportion of sample captured, but will produce more, smaller, sample volumes. Total samples collected can also be reduced with a divertervalve system that could collect, for example, every fifth revolution of the belt.

\section{Implications of "Skeleton" Belt with One Slot}

Using a single slot on a "skeleton" belt, that is, with no neighboring slots, the slot partition width becomes important because no confining pressure from other slots is present. A single slot should have very thin and sharp edges to even have a chance of collecting a suitable sample. With a single slot, high belt speeds might become significant because splash-out of sample would not have compensating splash-in. Additionally, high belt speeds reduce the effective slot "window" presented to a particle and large particles that should have been sampled are bounced from the slot edges with no compensating bounce from neighboring slots. For these considerations, single, sharp slots are not recommended.

\section{Implications of Several Neighboring Slots}

To overcome the implied problems of the single slot on a skeleton belt, a few "guard" slots are proposed on each side of the real sampling slot. One suggested configuration is shown in Fig. 2. It is reasonable to expect that thicker slot partitions would retard entry and require more guard slots to prevent lateral spreading. Very sharp slots may require only one or two guard slots. This would be expected to depend on the opening-to-slot-partition ratio but also on the ability of the slot assembly to convey the water away, as discussed later. A desirable partition thickness estimate can be made based on the effective slot width. If water is to enter the slot readily, most of the effective slot width should be the actual slot opening to prevent lateral spreading of the flow and reduce the need for large spreading distances in the flow direction that may exceed the belt width. However, if the slot partitions are too thin and flimsy, then accurate openings are difficult to maintain. If, for example, slots are $6 \mathrm{~mm}$ wide and the slot partitions are $3 \mathrm{~mm}$ thick, the effective slot width is $9 \mathrm{~mm}$ with an opening of $6 \mathrm{~mm}$, or the opening is twice the partition thickness and represents $2 / 3$ of the effective opening. This combination would need $1 \mathrm{~mm}$ of partition deviation to cause about $11 \%$ change in sampling rate. Thus, a sampling assembly with an achievable tolerance of construction within $10 \%$ seems well within reach. 


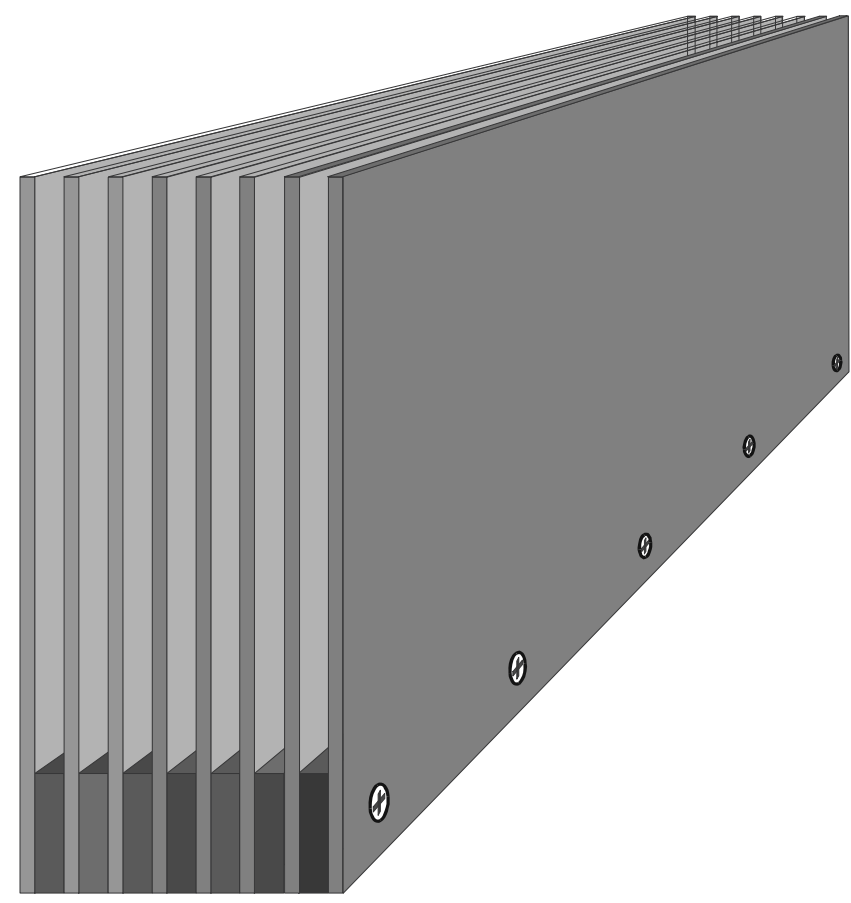

Fig. 2. Proposed sampler slot assembly to resist trash accumulation, flow from the center slot is collected, remaining slots act as guard slots

\section{Trash Tolerance of Slots}

As mentioned, partitions have been used with spacers in the slots to maintain accurate opening widths. The spacers tend to collect grass and weeds. Thus, a slot-assembly design that avoids such components and still maintains spacing is suggested. This design is used in Fig. 3, which is based on Fig. 2 and also suggests a field installation scheme.

\section{Slot Assembly Depth}

The depth of the slot assembly is based on the need to transport the sampled flow to the appropriate container. Because of the $10^{\circ}$ slope used to shed surface trash, the flow depth in the steeply sloping slots is likely to be less than the approach flow depth, despite the narrow slot width, and will probably be more on the order of the average vertical nappe thickness as it intersects the slot assembly. In the worst case, the slot will fill and the surface flow on the slots will extend downstream until the water surface slope in each slot is steep enough to transport the collected amount. According to the original concepts of a complete belt, any backpressure that prevents slot entry results in more spreading in the flow direction and eventual entry anyway. This can increase the number of guard slots needed to confine lateral spreading. Another negative aspect is that deeper slots would require a larger overfall step to accommodate them. The number of slots needed to limit lateral spreading is also a function of the approach channel depth and was estimated from the laboratory tests described later.

\section{Replacing Belt}

Actually using a belt, as described, is not particularly practical. The configuration suggested in Fig. 1 would quickly clog with debris between the belt and the turning drums. Using the top of the belt and shielding the bottom could avoid this, but could be more expensive than needed, and require increased overfall height.

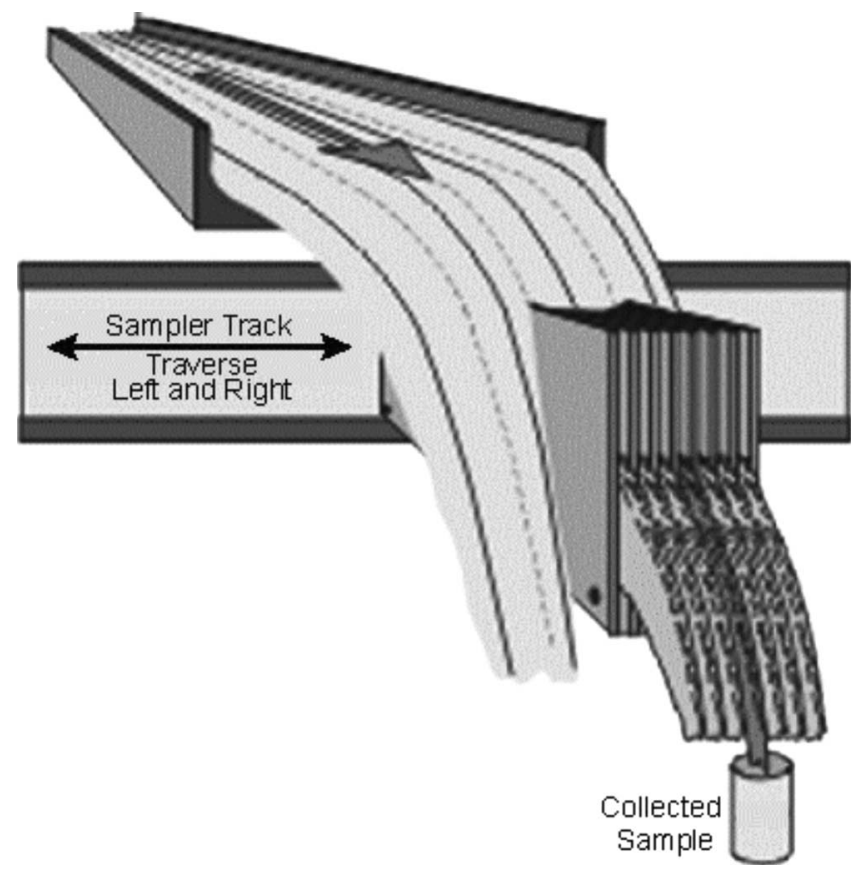

Fig. 3. Schematic of sampling assembly and traversing mechanism at a channel overfall

A more practical approach is to make a sampling assembly rack of several slots and traverse the assembly back and forth through the falling nappe. The sample proportion is still the ratio of the "effective" slot width and the "effective" belt length. Thus, if the belt is traversing at $100 \mathrm{~mm}$ per sec, and is considered to start at one side of the nappe at any distance, then hesitates at the other side before returning as the reverse cycle, and arrives at the starting point $180 \mathrm{sec}$ later, then it has made two trips through the nappe for an effective belt length that is halved, that is, $180 / 2 \mathrm{sec} \times 100 \mathrm{~mm} / \mathrm{s}=9,000 \mathrm{~mm}$ effective belt length. For a $9 \mathrm{~mm}$ effective slot width, the sample proportion would be $9 / 9,000=0.001$ of the flow rate, or volume, depending on the secondary collection equipment. Thus, the hesitation time becomes one way to adjust the sampling aliquot, as well as the changing of effective slot width and perhaps the use of diverter valves, as mentioned earlier. The effect of having different distances and hesitation times on each end of the traverse will affect the timing between the two samples in each cycle. This must be accounted for in the calculation of overall flow rate. This is avoided if a diverter valve omits sampling in one direction.

\section{Sampler as Flow Meter}

The precision of the sampler to allow flow volume and flow rate measurement means that it does not have to be associated with a flume or weir as have most previous samplers. This should allow installation at most sites that have enough overfall height to have accommodated a weir.

Some traversing samplers collect and hold the sample for dumping at the end of the cycle. This collector can be mounted at the end of the sampling assembly, but it must be protected from the floating trash and large rocks. Another scheme is to pipe the sample down and under to a container below the sampler assembly. This may require additional overfall height. 


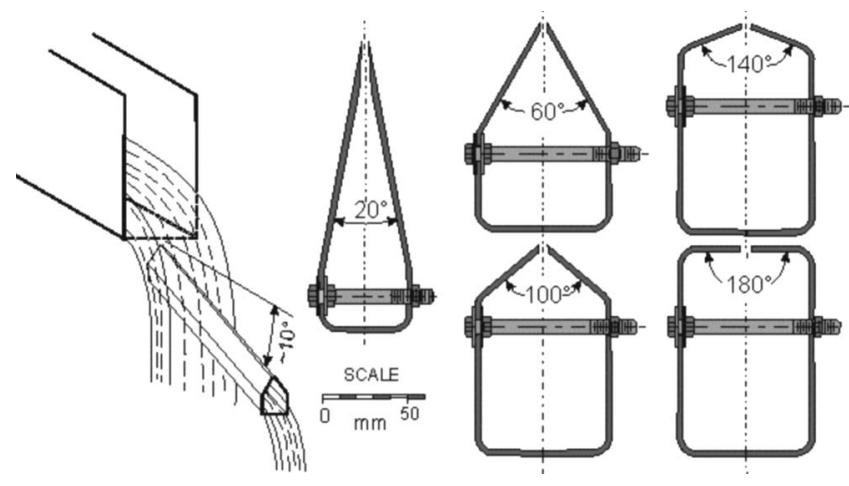

Fig. 4. Sediment-sampler assemblies of Barnes and Frevert (1954) and Barnes and Johnson (1956) (redrawn, used with permission)

\section{Partial History of Total-Load Samplers in Light of Ideal Sampler}

An examination of previous samplers (excluding all pump type samplers and "grab" samplers, etc.) to evaluate how well they approximate the ideal sampler is enlightening. Many of the previous sampler designs tried to intersect the nappe approximately perpendicular to the flow lines (Dendy, 1973; Renard et al. 1976). This had the disadvantage of catching grass-like fibers, and usually required a brush system somewhere in the traverse cycle. The ideal sampler concepts show that having the sampling slot perpendicular to the flow lines is of no advantage.

\section{Barnes et al. Sampler}

The basic configuration of the ideal sampler comes from Barnes and Frevert, (1954) and Barnes and Johnson (1956), [Fig. 4 (left)], who used a single-slotted, sharp-edged sampler assembly at a high overfall that was tilted downward in the direction of flow by about $10^{\circ}$, which they found to be self-cleaning of trash. They tested many single slot openings with variously tapered-top angles leading up to the sharp edged openings, Fig. 4 (right). The main results were that the tilt in the direction of flow from $5^{\circ}$ to $20^{\circ}$ did not affect sampling rate. However, their sampler did not sample the same ratio with changes in outside angle of the tapered slots. More important, it collected proportionally less of the sample with increasing flow rate, resulting in a catch ratio ranging from 100 to 180 , for their best configuration with a slot angle of $60^{\circ}$ (Fig. 4; top, middle figure). Their recommendation was to apply a complicated process of widening the slot toward the downstream end to try to return the sampling ratio to the original intent of 100 .

In light of the ideal sampler analysis, it would appear that the increasing pack pressure from increasing head losses of slot entry and lateral spreading were the cause of this decrease of sample with increasing flow rate. In the ideal sampler, this is automatically compensated by a slight spreading of the flow in the flow direction to use more length of slot opening without changing the sampling ratio.

\section{Coshocton Wheel Sampler}

The Coshocton Wheel sampler (USDA 1979) operates similarly to the ideal sampler. Instead of a belt, a cone is used to define the concepts. All the flow from the flume outlet crosses the surface of the cone. Effective slot widths in the cone surface should be ta- pered from zero at the apex to a selected proportion of the cone base circumference. Again, the guard slot idea could be employed, but fabrication would be more difficult than the belt concept because both the slot opening and the slot partitions would have to taper from zero to the selected proportion of the cone base circumference. The major faults with the original Coshocton Wheel samplers were that they did not rotate at a constant rate and the trajectory of the flow from the flume entered the slot and impacted the back wall of the slot and jetted out of the top. This caused a loss of particles and flow from the top part of the nappe (Replogle and Johnson 1963), distorting the catch sample. Replogle and Johnson (1963) present other shortcomings and a partial solution.

\section{Traversing Sampler with Parshall Flume}

Dendy (1973) devised a traversing system for the outlet of a Parshall flume that incorporates the traversing mechanism that is similar to that proposed for the ideal sampler. It had a vertical slot that was subject to catching grass and weeds. Its sampling accuracy was on the order of 10 to $30 \%$. He proposed using a sampling pause at each end of each traverse to reduce the sample size. Ultimately, he used a sample splitter of special construction that split the original sample into 13 parts. He states, "The relatively high sampling error for nearly all flow rates is not alarming since the sampler is not intended as a flow-measuring device." The Parshall flume described has a maximum operating head of about $75 \mathrm{~cm}$ and the installation requires a channel drop of at least $1 \mathrm{~m}$, or about 1.3 times the channel flow depth. He also lists proposed reasons for the relatively high deviations from theory. These are paraphrased here as:

1. Some head loss occurs as the fluid flows through the sampler slot, and this varies with the jet velocity.

2. The effective width of the slot is greater than the width of the actual slot opening. The effective width is approximately equal to the width of the opening plus one-half the thickness of the two slot edges, and affects the aliquot.

3. Splashing around the sampler may cause a small portion of the liquid to be sampled twice.

4. The sampling rate will be less at high sampler travel speeds. Presumably this would have little effect at sampler speeds less than 8 or $10 \mathrm{~cm} / \mathrm{s}$.

Using the concepts of the ideal sampler, reason 1 appears correct in recognizing that the friction of entry increases with velocity. However, this configuration does not allow automatic correction, as does the ideal sampler, which would compensate by using more of the slot length. Reason 2 is correct in that the effective slot width is a function of the edge thickness. Again, the effective opening, without the guard slots of the ideal sampler, because of lateral spreading, would not precisely use half of each slot edge. Reason 3 recognizes the splash problem that the ideal sampler would handle because of the opportunity for equalizing splash-in and splash-out due to the guard slots. Reason 4 is probably correct because of the probability of increased splash-out and the resulting angle of attack of the slot assembly surface to the flow vectors. Again, sufficient guard slots, according to the idealsampler concepts, would compensate these behaviors.

\section{Multistaged and Stationary Sampler Design}

In about 1975, our laboratory personnel applied part of the sampler concepts, as understood at that time, to the construction of a multistaged sampler system that incorporated some of the ideas of 
the Barnes and Frevert (1954) sampler and the Coshocton wheel modification of Replogle and Johnson (1963). It was applied to small watersheds in Hawaii for studies of erosion from sugar cane and pineapple fields.

Because we sampled at the outlet of a trapezoidal longthroated flume (Clemmens et al. 2001), and not the rectangular overfall of Barnes and Frevert (1954), the idea was to use many sloping samplers. No guard slots were considered in 1975 and sharp-edged samplers were envisioned. Each of the slots in the flow nappe would fill its corresponding container, representing its width share. As with the Fig. 1 concept, the entire storm event would be in the sample containers, but this time, they would all differ according to the overfall shape. The problem reduces to selecting enough slots across the overfall to enable the flow event to be reconstructed to some decided level of accuracy.

We used nine slotted samplers in the 1975 work with knifesharp edges mounted on a $10^{\circ}$ slope. A trapezoidal critical depth flume formed the flow nappe and had a design capacity of $0.6 \mathrm{~m}^{3} / \mathrm{s}$. The flume was computer calibrated by the methods most recently updated and described in Clemmens et al. (2001). The attempt was to create a sharp edge on the slot to form a zero partition thickness. As shown by the more recent ideal-sampler concepts, guard slots should have produced more accurate results.

The primary sampler reduced the maximum flow for a secondary sampler to less than $15 \mathrm{l} / \mathrm{s}$, which was in the range of the smaller Coshocton wheel styles. Instead of an original Coshocton wheel, we used the modification proposed by Replogle and Johnson (1963). This basically dumped the flow into a short bucket that had an annular slot about $1.5 \mathrm{~cm}$ wide cut out around its bottom at the extreme edge. This annular curtain of water was then sampled by a rotating slot copied from a portion of an original Coshocton wheel that was placed under the bucket. The details and laboratory findings of this system and the field application were reported by Replogle and El-Swaify (1985).

\section{Laboratory Tests}

A sampler assembly similar to that shown in Fig. 2 was constructed for laboratory evaluation. It contained three guard slots on each side of an extended central slot. The slot openings were constructed from aluminum sheet and bar stock and were $6.3 \mathrm{~mm}$ (1/4 in.) wide, with the slot partitions being $3.2 \mathrm{~mm}(1 / 8 \mathrm{in}$.) wide.

Because we did not have access to a traversing mechanism, we created a rectangular weir overfall from a leaf gate to check the sampling rate that should represent the effective slot width ratio to the weir width. The sloping leaf gate allowed the sampler to be readily inserted beneath the resulting nappe. As mentioned, we constructed the slot assembly from commercial aluminum bar stock and installed it below the weir nappe in various installations from parallel with the flow to about $15^{\circ}$ angled to the flow. However, the assembly was always sloping downward in the direction of the flow by about $10^{\circ}$ (Fig. 5). The flow rate over the leaf gate was measured with the laboratory weigh-tank system that had a nominal accuracy to within about $0.1 \%$. The sample collection was weighed on a separate and smaller weigh-tank system, again to within about the same error.

For testing, we did not wish to accept the approximately $0.8 \mathrm{~mm}$ variability in slot width resulting from the assembly of randomly selected pieces of bar stock, which could cause about 9\% variation in sample collected. Presumably, with careful selection to match adjacent partition pieces, this could be reduced. To

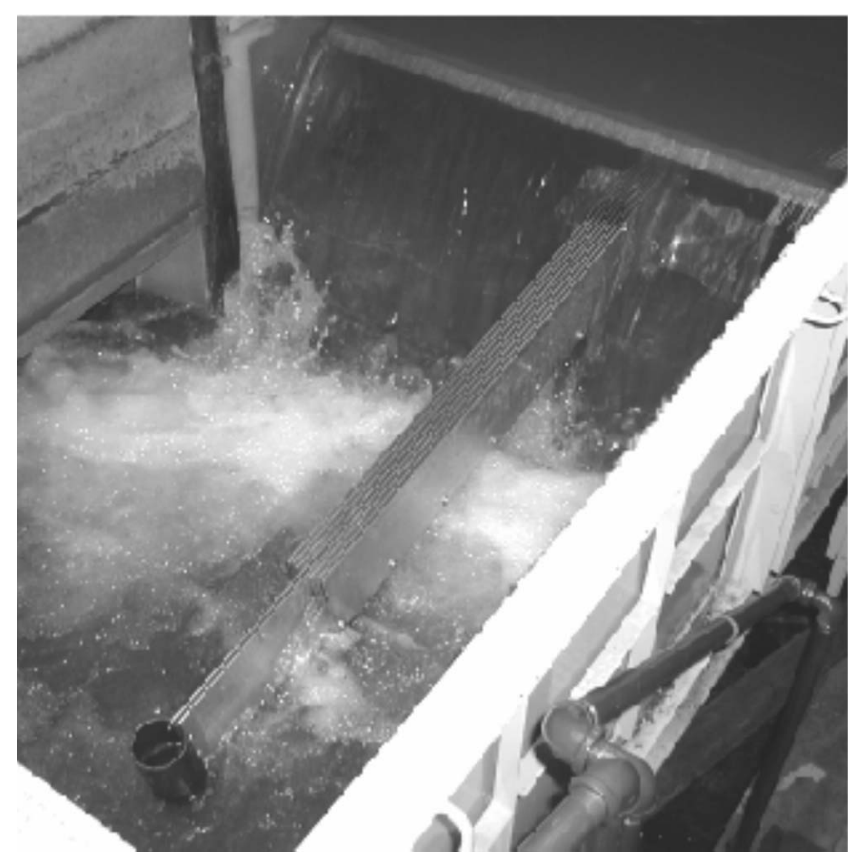

Fig. 5. Sampler assembly with collector on the downstream end of the extended center slot

adjust to the test situation, we resorted to a procedure that would not conveniently translate to the field, in that we measured the average width of the slot used by the nappe for each increment of test flow rate. Thus, each flow point is compared to what should be expected for that slot width used by the nappe.

The corrections did not bring the results into uniform compliance within our expectations of $\pm 2 \%$ so we examined the partition tops carefully and found that the machine-sheared edges had cross-slopes such that the partitions split the sample unevenly to the left and right, not always in the same direction. To correct this haphazard bias, we used a flat machinist's file and filed the top of the assembly until it was flat across. The results were more consistent and showed that at higher flows, the sampling rack was not wide enough to force the sample into the slots and some sample was lost to lateral spreading.

This observation on insufficient width is shown in Fig. 6. Note in the topmost front and side view photos that the intersection of the nappe underside with the sampling assembly makes a curve that can be seen through the clear water. The front intersection is outlined by the photo flash reflections. The outlined oval shape is interpreted to mean that there is lateral escape of sample, which is computed to be well in excess of $8 \%$. Note that in the lower front and side view photos, these lines are straight, interpreted to mean that at these smaller flows, the lateral escape is contained resulting in a computed error near $0 \%$.

The tests indicated that the needed constructed width perpendicular to the flow of this rack section that represents the belt segment is related to the overfall channel flow depth and the sum of the slot openings. When the rack is composed of sufficient slots so that the slot-width sum is more than half the channel overfall depth, the system undersampled from 0 to $2 \%$ but when there are insufficient slots whose sum represents less than one-third of the overfall depth, the system undersampled by over $8 \%$. (Fig. 6). 


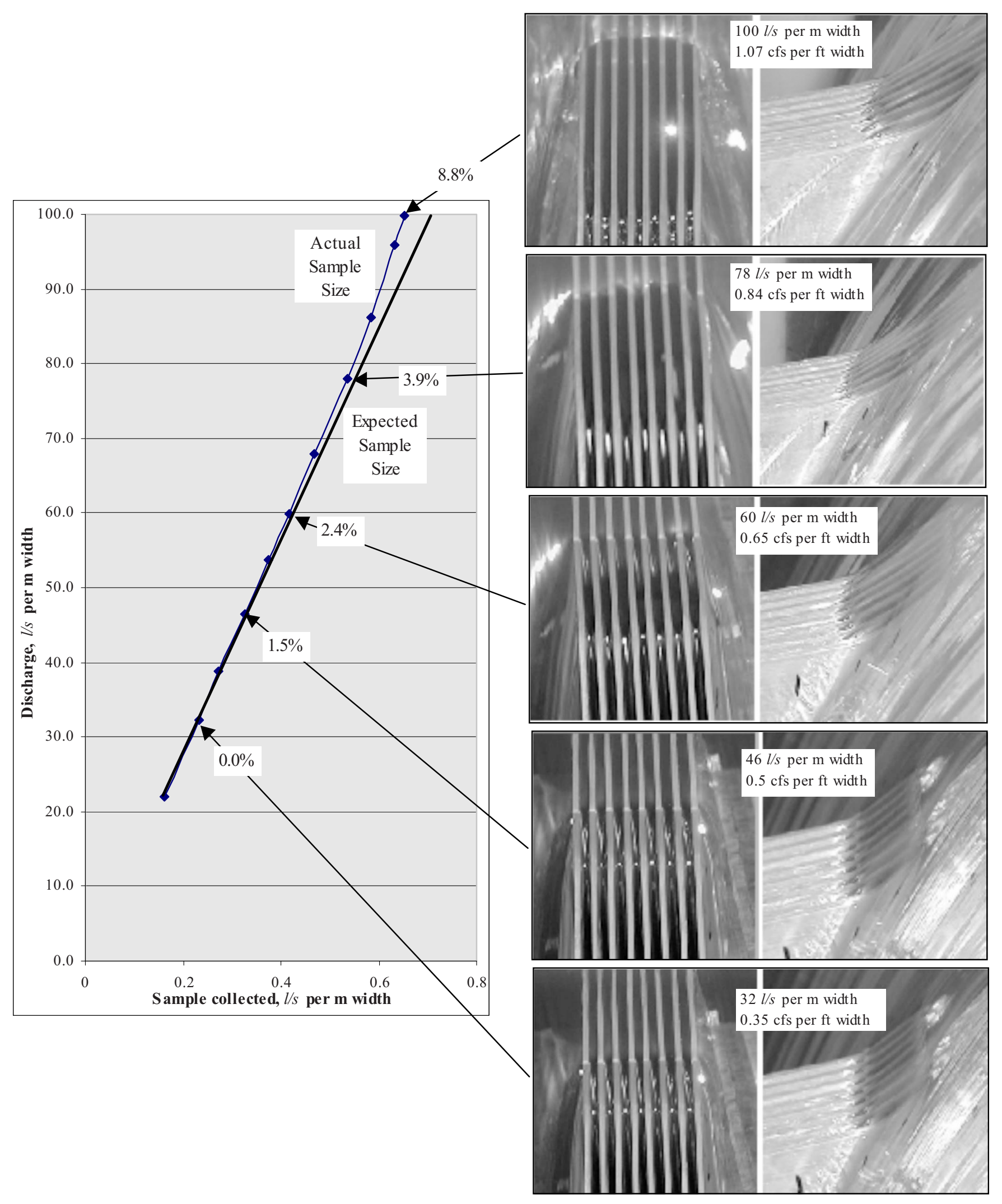

Fig. 6. Deviation of collected sample from expected sample, note the curvature of the upper and lower edges of the nappe intersection with the sampler assembly at higher flows 


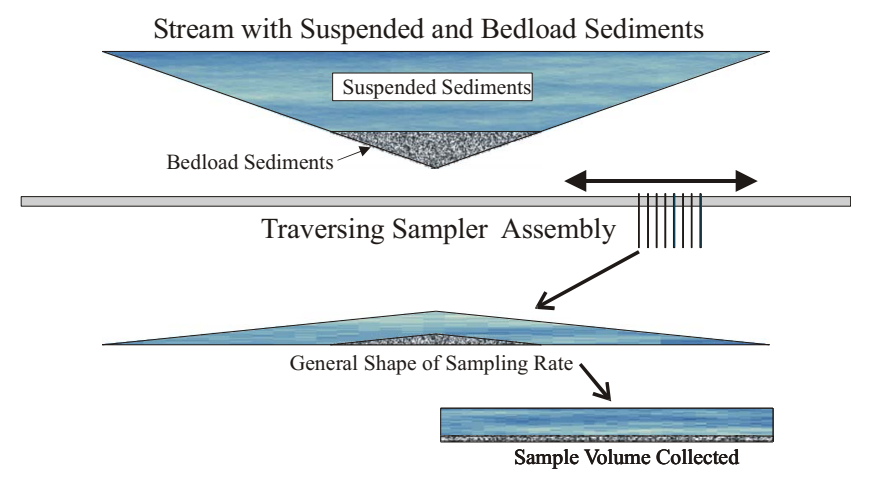

Fig. 7. Expected pattern of suspended and bed-load sediment collection by traversing sampler assembly

\section{Extensions of Concepts to Stationary Sampler Assemblies}

Further extensions of the concepts led to sampler proposed designs that can serve in locations without power, and guide design of sample splitters to reduce sample size.

Suppose now, that our conveyor belt halts. What are the consequences? As mentioned earlier, even a halted belt should be useful. If as many as 10 to 20 slot-assembly sets can be placed at even spacings across the overfall opening, then the combined sample collected will have a statistical contribution from each portion of the width.

Standard textbook stream sampling for velocity recommends 20 evenly spaced locations across a streamflow to approach within about $2 \%$ accuracy. A rectangular overfall should provide this accuracy with the fewest sampling-slot assemblies, but an irregular overfall should also work with an increased number of assemblies. This is likely to produce a large sample and will require an accurate sample splitter. Consider Fig. 7. If a triangular channel is fitted with a traversing sampler assembly, as in Fig. 7, the sample being collected might accumulate in a triangular fashion as suggested. The beginning and ending edges of the traverse would collect small amounts of sample from small amounts of the total flow and the center region would provide the bulk of the sample from the bulk of the flow, in approximate proportion. The actual volume of sample collected would depend on the parameters described earlier. Now if the traversing assembly is replaced by a series of stationary sampling assemblies as indicated in Fig. 8 , and each is constructed much like the single traversing assembly, but are uniformly spaced across the channel overfall, then the

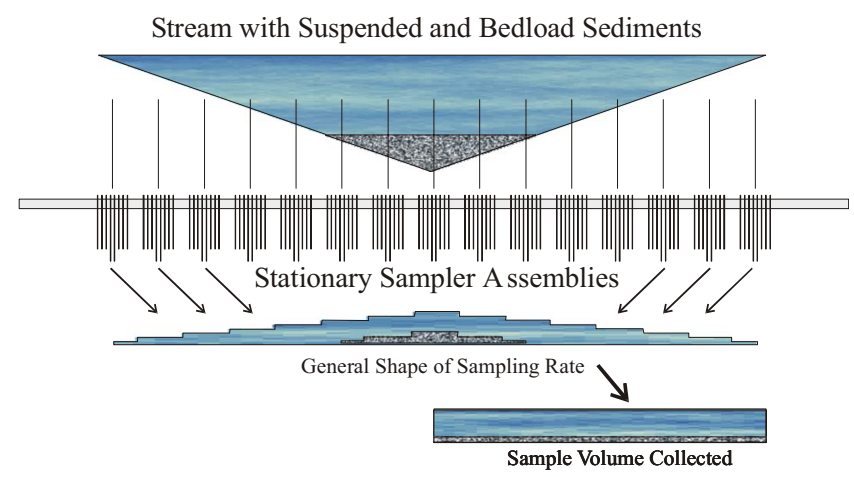

Fig. 8. Expected pattern of suspended and bed-load sediment sampling by a number of stationary sampler assemblies

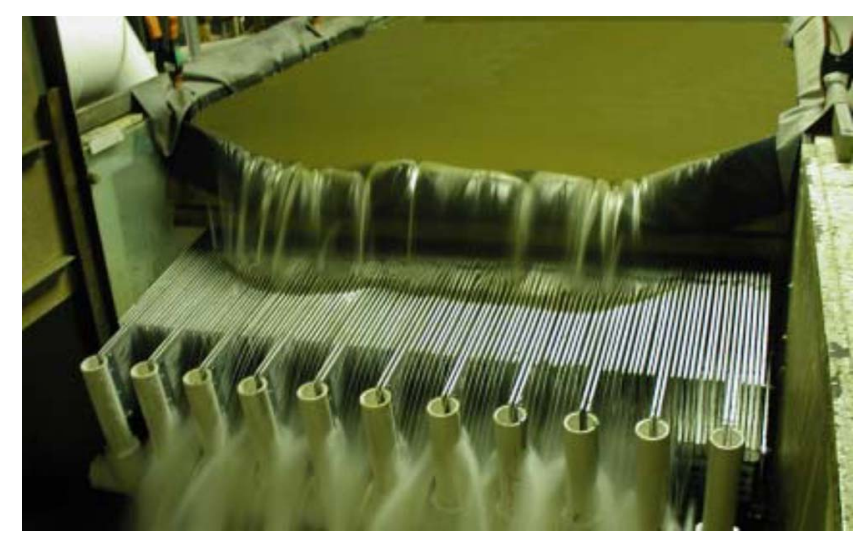

Fig. 9. Sampling assembly to test the concept of "stopped" conveyer belt system

collected sample accumulation might look something like that shown in Fig. 8. The sample size, however, cannot be adjusted with speed changes and waiting times, as with the traversing sampler, and measures to reduce the volume are likely to be needed because the proportion of the flow collected would be the fixed ratio of the effective slot opening to the spacing of the individual sampler groups.

Reasonably satisfactory results can be expected from these stationary samplers if a sufficient number of sampling slots are provided across the nappe to approximate the behavior of the true flow event to a selected level of accuracy. Thus, this arrangement provides a proposed scheme for sites without adequate power.

Up to nine samplers have worked well in field practice; however, even without using the guard-slot concept. If a single sampler and guard-slot assembly is used, then the overfall should be rectangular and some means must be provided to assure that the velocity distribution and sediment load are laterally uniform. The clearing of leaves and small trash that can cover the slots may be more difficult than that for a traversing sampler where brushes at the end of the traverse might suffice. One possibility is the periodic raising of wires from the slot bottoms.

\section{Partial Test of Concept}

A wide stationary rack was constructed (Fig. 9) using the same openings and partition sizes as the previous single slot assembly. Ten nonsampling slots accompanied each sampling slot. The entire assembly was placed under an irregular overfall with a cross section approximating a rough trapezoid with a high center (Fig. 9). When using standard "mill-run" flat aluminum stock, it was difficult to find lengths that did not have some warp in them. This resulted in variability in the slot spacing. This was not deemed highly important for the so-called guard slots, but is more important for the sampling slots themselves. The 11 sampling slots were measured with a caliper. These measurements are shown in Table 1 , from left to right when facing the direction of flow. The edges were not modified with a file as they were in the previous tests.

All 11 sampling slots participated at the upper $15 \%$ of flow range, but only six contributed at the lowest $8 \%$ of the range, which was 4.8 to $621 / \mathrm{s}$. Recall that increasing the number of involved samplers is expected to improve accuracy. Because this overfall was more or less trapezoidal, the incremental increase in catch as each sampling slot became involved was less than the spacing interval represented, resulting in a rather smooth increase. Fortuitously, in this bolted-together assembly, a too-narrow slot 
Table 1. Measured Slot Width and Deviation from Planned Width of $0.635 \mathrm{~cm}(0.25$ in.)

\begin{tabular}{lccc}
\hline & \multicolumn{2}{c}{ Slot width } & \\
\cline { 2 - 3 } Slot number & in. & $\mathrm{cm}$ & Deviation $(\%)$ \\
\hline 1 & 0.242 & 0.615 & -3.20 \\
2 & 0.247 & 0.627 & -1.20 \\
3 & 0.260 & 0.660 & 4.00 \\
4 & 0.247 & 0.627 & -1.20 \\
5 & 0.231 & 0.588 & -7.48 \\
6 & 0.269 & 0.682 & 7.48 \\
7 & 0.251 & 0.638 & 0.40 \\
8 & 0.264 & 0.671 & 5.60 \\
9 & 0.246 & 0.624 & -1.80 \\
10 & 0.256 & 0.650 & 2.44 \\
11 & 0.258 & 0.655 & 3.20 \\
Average & 0.252 & 0.640 & 0.75 \\
\hline
\end{tabular}

and a too-wide slot (Nos. 5 and 6, Table 1) were placed in the center where they somewhat compensated, as far as catch volume is concerned.

Unlike the moving sampler, where the shape of the overfall is not a factor, there is a case where the stationary sampler is not expected to function well. Suppose the overfall is convex downstream, more or less a mild imitation of a duckbill weir, then if a side of the duckbill weir overfall were parallel to the slots, the result would be underrepresentation for that sector if the flow missed the slot, and overrepresentation if it coincided with a slot. This is most likely in our test setup at the lower flows (Fig. 9). A rectangular overfall that avoids curved ends is recommended.

In the tested construction, there were 11 groups of 10 nonsampling slots, with each eleventh slot being collected. The sample flow rate versus the total overfall channel flow rate was determined with the laboratory weigh tank system as described for the original test assembly (Fig. 10). Because the sample was removed from the main flow before the main flow was weighed, the plotted relation includes the sample weight added to the main flow weight to obtain the total channel flow rate. The wide scatter near the lower quarter of the plot is attributed to the curved-end effects of the overfall nappe described above. A trend line through all points indicates about $4 \%$ systematic oversampling of the flow. This systematic oversampling might partly be attributed to tiny streamlets that ride the $3 \mathrm{~mm}$ wide top edges of the sampling slots and run into the sample gathering pipes. These streamlets from the intermediate slots are visible in the center portion of Fig. 9. This small amount fails to split to either side. However, the amount carried visually appears to be constant and, therefore, would not be a systematic $4 \%$ oversampling. If the slots were made from materials that have a rounded top edge, or even a uniform side-sloping top edge, it should eliminate the streamlets and any effects they contribute. Note that if the top edges have a side slope, all edges must slope in the same direction.

\section{Flow Measuring Device}

As a flow measuring system, the present setup predicts a total streamflow that is 11 times the sample rate, as mentioned above because the large weigh-tank system is downstream from the smaller sample withdrawal and the two weighed discharges must be summed (sample $q$ plus main flow $Q$ ). The field challenge is then how to measure the small sample. Because of the reduced volume, and the sediment loadings, this measurement will need some careful design. Flow measuring flumes are to be avoided because of the sediment loadings. Large volume tanks are a possibility, as are large tipping-bucket designs, which can handle sediment loads. Somewhere in the system, a representative sample is usually collected for analysis, so the measurement system must provide for this. Often the sample size must be further proportionally split to reduce the final sample to convenient size.

\section{Recommendations for Alternative Sampler Assembly Construction}

In large field installations, the construction of the sampler assembly used here would be expensive in terms of materials and assembly difficulty. Because the tops of the slots need to be uniformly reproduced for accurate results, some ideas for doing this are presented in Fig. 11. The top diagram is made up of structural angles welded together and may have difficulties con-

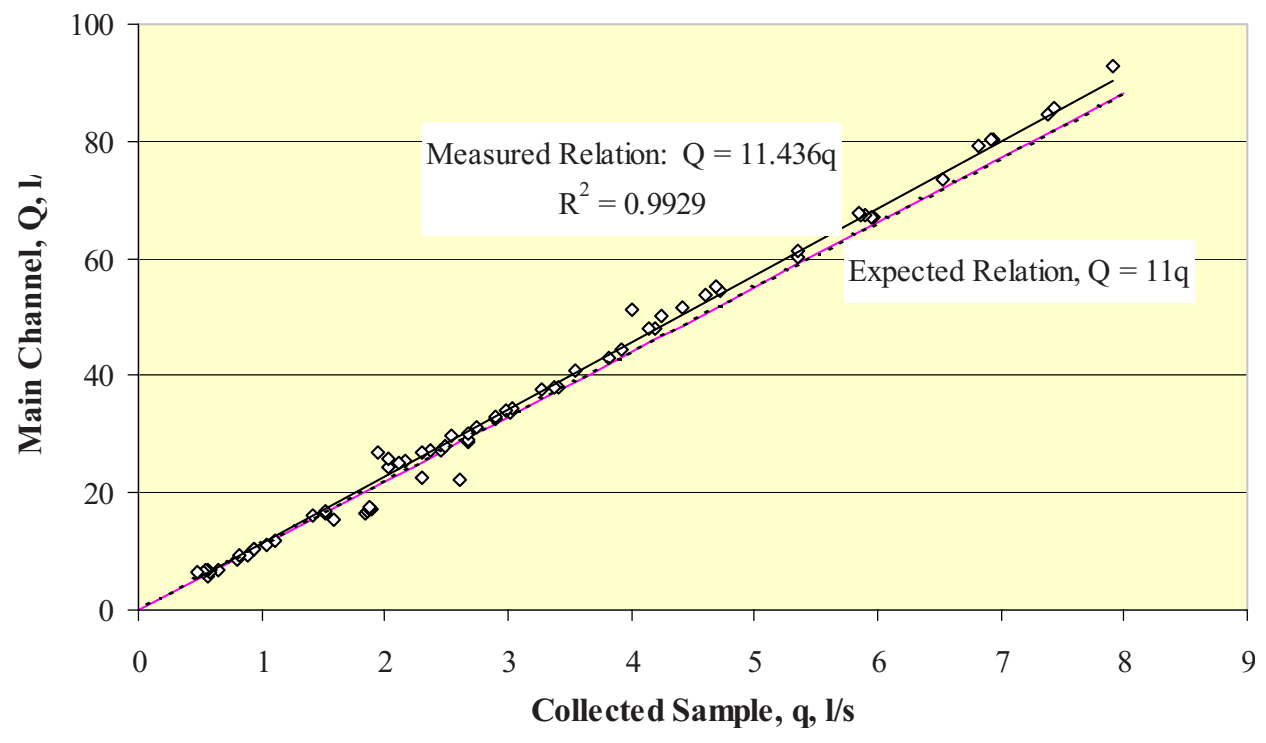

Fig. 10. Sample and bypass flow 


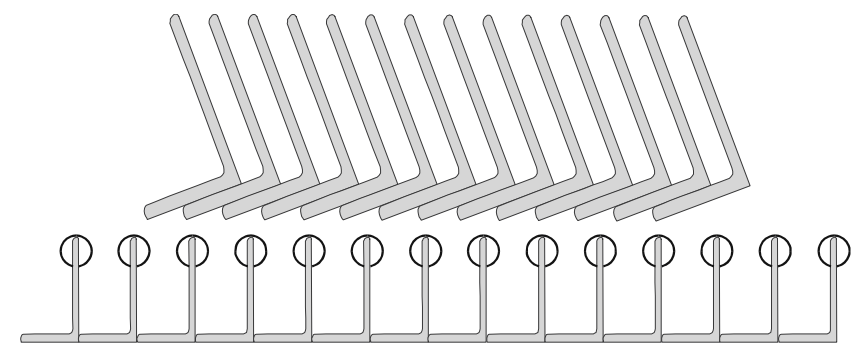

Fig. 11. Suggestions for alternative construction of the sampler assembly using structural angles, or a combination of slotted tubing and structural angle

veying the sample away from the site unless the angles are thin and one angle edge is tall. A slotted tube placed over the top edges of a structural member as shown in the bottom part of Fig. 11 would at first appear to allow extra flow space. However, because the width between centers of the sampler slots, whether it is flat-stock edges or round tubing, determines the flow to be handled, simply widening the spacing of the vertical members and adding round tubing does not reduce the need to have deep sampling assemblies as described in the section on "Theoretical Considerations." What it does offer is the opportunity to place small stainless steel tubing on the top edges of iron structural members to reduce the effects that rusting would have on the slot widths. Rusting can be slowed in the usual ways with coatings on exposed parts, but if the coatings fail, using the stainless tubing in the sensitive location on the slot tops can reduce the rusting effects.

\section{Design Recommendations}

Recommendations for the design of a practical total load sampler and flow measuring system are as follows:

Select a site that can provide an overfall about $50 \%$ greater than the maximum channel flow depth for deep channels, with a minimum of about $1 \mathrm{~m}$ for even small channels. Lesser overfall heights may work at greater expense, including pumping of a downstream pool.

Fit a traversing mechanism with a slotted sampler assembly having enough guard slots that will have an aggregate opening width greater than half the channel depth to be sampled. This sampler assembly should be mounted with a $10^{\circ}$ downstream slope to help pass debris. Select slots as wide as the maximum particle diameter of interest to be collected. Partition walls should be smaller than slot widths to reduce the need for sample spreading, and, thus, wide and heavy sampler assemblies.

Slot partitions can theoretically be sharpened, provided they are all sharpened similarly, but knife-edged sharpness may actually retard self-cleaning. Brushes or other slot cleaning equipment may be fashioned to help mitigate trash and leaves that might spoil the sampling results.

Provide alternating current power to operate the traverser, if possible, because an oversized AC motor can provide nearly constant speed for the traversing mechanism, whereas universal wound and DC motors tend to slow if the loads change. Precise knowledge of the actual constant speed of the motor is not required because the sample percentage is the ratio of the effective slot width to the effective belt length, which can be manipulated by waiting periods at the end of a traverse. Note that in the case of back and forth traversing, the effective belt length is halved.
Cycle counters and diverter valves are suggested as a practical way to reduce sample size. For example, every tenth traverse can be collected. Keeping the sample on only one end of the traverse will reduce it by half.

If the system can be constructed as described and time delivery and the volume of samples are recorded so that flow rate can be determined, then direct sampling from any overfall without a flume is recommended because flumes tend to disrupt the movement of sediments by delaying it with respect to its movement in the original channel. Again, overfall shape is unimportant.

\section{Summary and Conclusions}

A total-load sediment sampler design is proposed that samples total bed load plus suspended load, and can be used as a flow measuring device, even in a poorly defined channel cross section. It should be capable of installation at sites that can provide an overfall height about equal to the maximum streamflow depth. An entire sampler has not been built, but each subcomponent has enough operational experience to support confidence in the integrated total device. The concept is based on a long, wide, moving conveyor belt, with slots in the belt, which is placed beneath a stream overfall. All of the flow must fall through the slots, and with equal sized slots, each must catch a similar proportion of the total flow. Hence, only one slot needs to be collected.

A test rack with several slots, representing a small section of the total conveyor belt, was imagined to be traversed back and forth through the falling nappe. Sediment and flow samples are collected from only the center-most slot. Laboratory tests of this sampling-assembly rack indicated that its constructed width is related to the overfall depth and the sum of the slot openings. When the overfall depth is less than twice the sum of these flow slot-width openings in the rack, the collected sample systematically undersampled by less than $2 \%$. As the overfall depth approaches three times the sum of these slot-width openings, the rack undersampled by over $8 \%$. This is attributed to the failure of the tested sampling rack to be wide enough to adequately prevent significant side spreading of the nappe during sampling. This design parameter and overall design suggestions are discussed. The proportion caught can be adjusted to collect a predetermined sampling size.

The concepts are extended to the condition with a stopped belt where several sampling-slot groups are equally spaced beneath the overfall. Tests using 11 sampling-slot groups placed beneath an irregularly shaped overfall were conducted. Each samplingslot group had five guard slots on each side of the sampled slot. This collected total sample agreed with the expected sample to within $4 \%$.

\section{Recommendations for Further Work}

The general concepts discussed should be applicable to other applications such as rain-gage design and setups for testing irrigation sprinklers.

\section{Acknowledgments}

The writer thankfully acknowledges the laboratory assistance of Trathferd (Skip) Eshelman and Allan Knopf for the collection of the laboratory data and important observations of the flow behav- 
iors that were vital in explaining the test results and establishing the validity of the concepts.

\section{References}

ASCE. (1969). Sediment measurement techniques: A. Fluvial sediment, Task Committee on Preparation of Sedimentation Manual Committee of the Hydraulics Division, American Society of Civil Engineers, Vol. 95, HY5, 1477-1514 (subsequently part of Manual 54, sedimentation engineering).

Barnes, K. K., and Frevert, R. K. (1954). "A runoff sampler for large watersheds. Part I. Laboratory studies.” Agric. Eng., 35(2), 88-90.

Barnes, K. K., and Johnson, H. P. (1956). "A runoff sampler for large watersheds. Part 2. Field installations.” Agric. Eng., 37(12), 813-815, 824.

Brown, H. E., Hansen, E. A., and Champaigne, N. E., Jr. (1970). "A system for measuring total sediment yield from small watersheds." Water Resour. Res., 6(3), 818-825.

Clemmens, A. J., Wahl, T. L., Bos, M. G., and Replogle, J. A. (2001). "Water measurement with flumes and weirs." Publication No. 58, Int. Institute for Land Reclamation and Improvement, Wageningen, The Netherlands.

Dendy, F. E. (1973). "Traversing-slot runoff sampler for small watersheds." ARS-S-15, U.S. Sedimentation Laboratory, Agricultural Re- search Service (Southern Region), USDA, Oxford Miss.

Parsons, D. A. (1954). "Coshocton-type runoff samplers." SCS-TP-124, Laboratory Investigations, Soil Conservation Service, USDA, Washington, D.C.

Parsons, D. A. (1955). "Coshocton-type runoff samplers." Supplementary Laboratory, Investigations at the Stillwater, Oklahoma Outdoor Hydraulics Laboratory, ARS-41-2, Agricultural Research Service, USDA, Washington, D.C.

Renard, K. G., Simanton, J. R., and Donica, L. E. (1976). "A time related automatic total-load sediment sampler." Proc., Third Federal Interagency Sedimentation Conf., Symp. 7, U.S. Government Printing Office, PB 245 100, Washington, D.C., 17-29.

Replogle, J. A., and El-Swaify, S. A. (1985). "Design and construction considerations for sediment sampling of streamflows." Proc., Int. Conf. on Soil Erosion and Human Resources, 139-148.

Replogle, J. A., and Johnson, L. C. (1963). "Improved measuring and sampling equipment for sediment-laden runoff." Trans. ASAE, 6(3), 259-261.

USDA. (1979). Field manual for research in agricultural hydrology. Agricultural handbook No. 224, revised February 1979, U.S. Dept. of Agriculture.

Wang, J. Y., Hermanson, R. E., and Hendrick, J. G. (1971). "Modification of H-flume and Coshocton wheel system." Trans. ASAE, 14(6), 10151017. 